Supporting Information for J. Org. Chem.

\title{
Synthesis and Conformational Studies of a [-Turn Mimetic Incorporated in Leu-Enkephalin
}

\author{
David Blomberg, ${ }^{\dagger}$ Mattias Hedenström, ${ }^{\dagger}$ Paul Kreye, ${ }^{\dagger}$ Ingmar Sethson, ${ }^{\dagger}$ Kay \\ Brickmann $^{\#}$ and Jan Kihlberg ${ }^{\dagger * *}$ \\ †'Organic Chemistry, Department of Chemistry, Umeå University, SE-901 87 Umeå, \\ Sweden and ${ }^{\#}$ AstraZeneca R\&D Mölndal, Sweden. \\ jan.kihlberg@chem.umu.se
}

Table of contents:

S4: ${ }^{1} \mathrm{H}$ NMR for compound 7

S5: ${ }^{13} \mathrm{C}$ NMR for compound 7

S6: ${ }^{1} \mathrm{H}$ NMR for compound 8

S7: ${ }^{13} \mathrm{C}$ NMR for compound 8

S8: ${ }^{1} \mathrm{H}$ NMR for compound 9

S9: ${ }^{13} \mathrm{C}$ NMR for compound 9

S10: ${ }^{1} \mathrm{H}$ NMR for compound 10

S11: ${ }^{13} \mathrm{C}$ NMR for compound 10 
S12: ${ }^{1} \mathrm{H}$ NMR for compound 11

S13: ${ }^{13} \mathrm{C}$ NMR for compound 11

S14: ${ }^{1} \mathrm{H}$ NMR for compound 12

S15: ${ }^{13} \mathrm{C}$ NMR for compound 12

S16: ${ }^{1} \mathrm{H}$ NMR for compound 13

S17: ${ }^{13} \mathrm{C}$ NMR for compound 13

S18: ${ }^{1} \mathrm{H}$ NMR for compound 15

S19: ${ }^{13} \mathrm{C}$ NMR for compound 15

S20: ${ }^{1} \mathrm{H}$ NMR for compound 16

S21: ${ }^{13} \mathrm{C}$ NMR for compound 16

S22: ${ }^{1} \mathrm{H}$ NMR for compound 17

S23: ${ }^{13} \mathrm{C}$ NMR for compound 17

S24: ${ }^{1} \mathrm{H}$ NMR for compound 18

S25: ${ }^{13} \mathrm{C}$ NMR for compound 18

S26: ${ }^{1} \mathrm{H}$ NMR for compound 19

S27: ${ }^{1} \mathrm{H}$ NMR for compound 21

S28: ${ }^{1} \mathrm{H}$ NMR for compound 23 
General methods and materials. ${ }^{1,2}{ }^{1} \mathrm{H}$ and ${ }^{13} \mathrm{C}$ NMR spectra were also recorded in $\mathrm{CD}_{3} \mathrm{OD}$ (residual $\mathrm{CD}_{2} \mathrm{HOH}(\square=3.35$ or 4.78$)$ or $\mathrm{CD}_{3} \mathrm{OD}(\square=49.0)$ and $\left(\mathrm{CD}_{3}\right)_{2} \mathrm{~S}=\mathrm{O}$ (residual $\left(\mathrm{CD}_{2} \mathrm{H}\right)_{2} \mathrm{~S}=\mathrm{O}(\square=2.49)$ or $\left(\mathrm{CD}_{3}\right)_{2} \mathrm{~S}=\mathrm{O}(\square=39.5)$ as internal standard $)$ at $298 \mathrm{~K}$ unless otherwise stated. Purification by HPLC was run with $100 \% \mathrm{H}_{2} \mathrm{O}(0.1 \%$ TFA) $\square \quad 100 \%$ $\mathrm{CH}_{3} \mathrm{CN}\left(0.1 \%\right.$ TFA) over a period of $1 \mathrm{~h} .{ }^{1} \mathrm{H}-\mathrm{NMR}$ signals are assigned with support from appropriate 2D-NMR spectra and are presented in the supporting information. Combustion analysis was obtained for selected compounds.

\section{References}

(1) Brickmann, K.; Yuan, Z.; Sethson, I.; Somfai, P.; Kihlberg, J. Chem. Eur. J. 1999, 5, 2241-2253.

(2) Yuan, Z.; Blomberg, D.; Sethson, I.; Brickmann, K.; Ekholm, K.; Johansson, B.;

Nilsson, A.; Kihlberg, J. J. Med. Chem. 2002, 45, 2512-2519. 


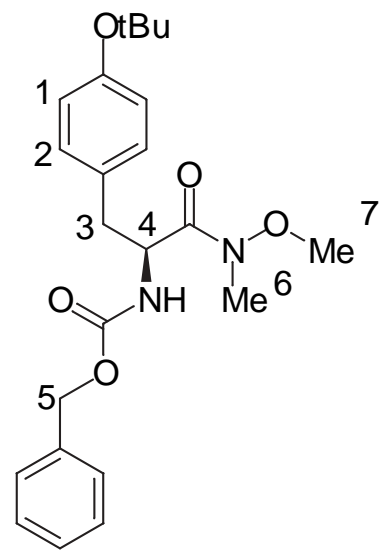

Cbz-arom

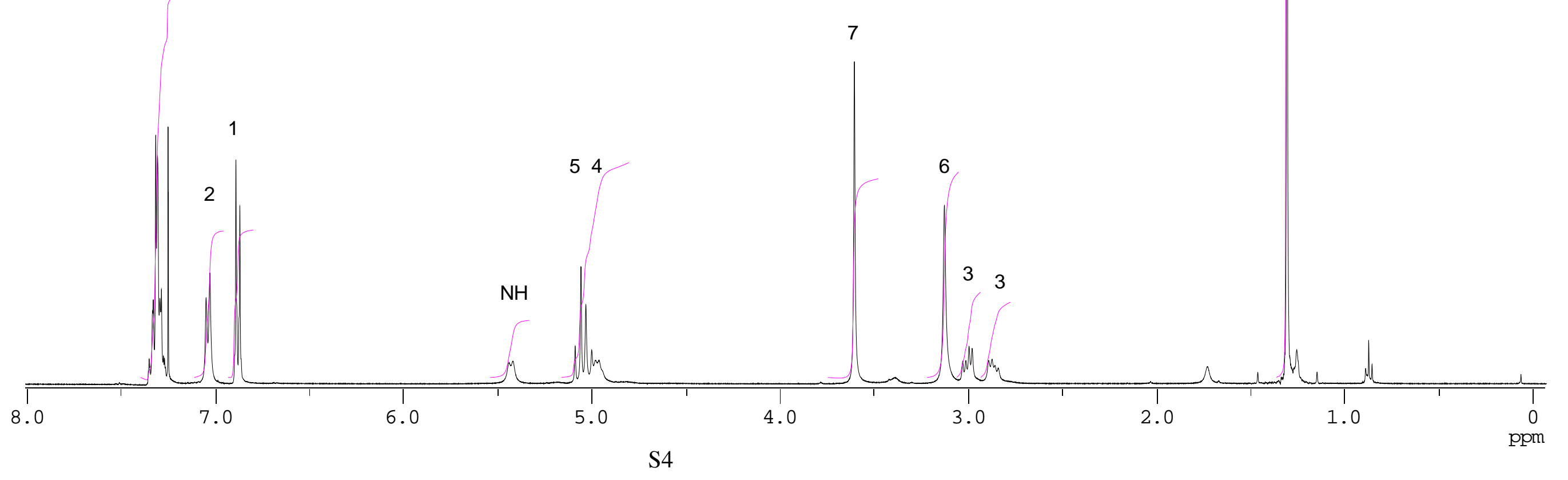



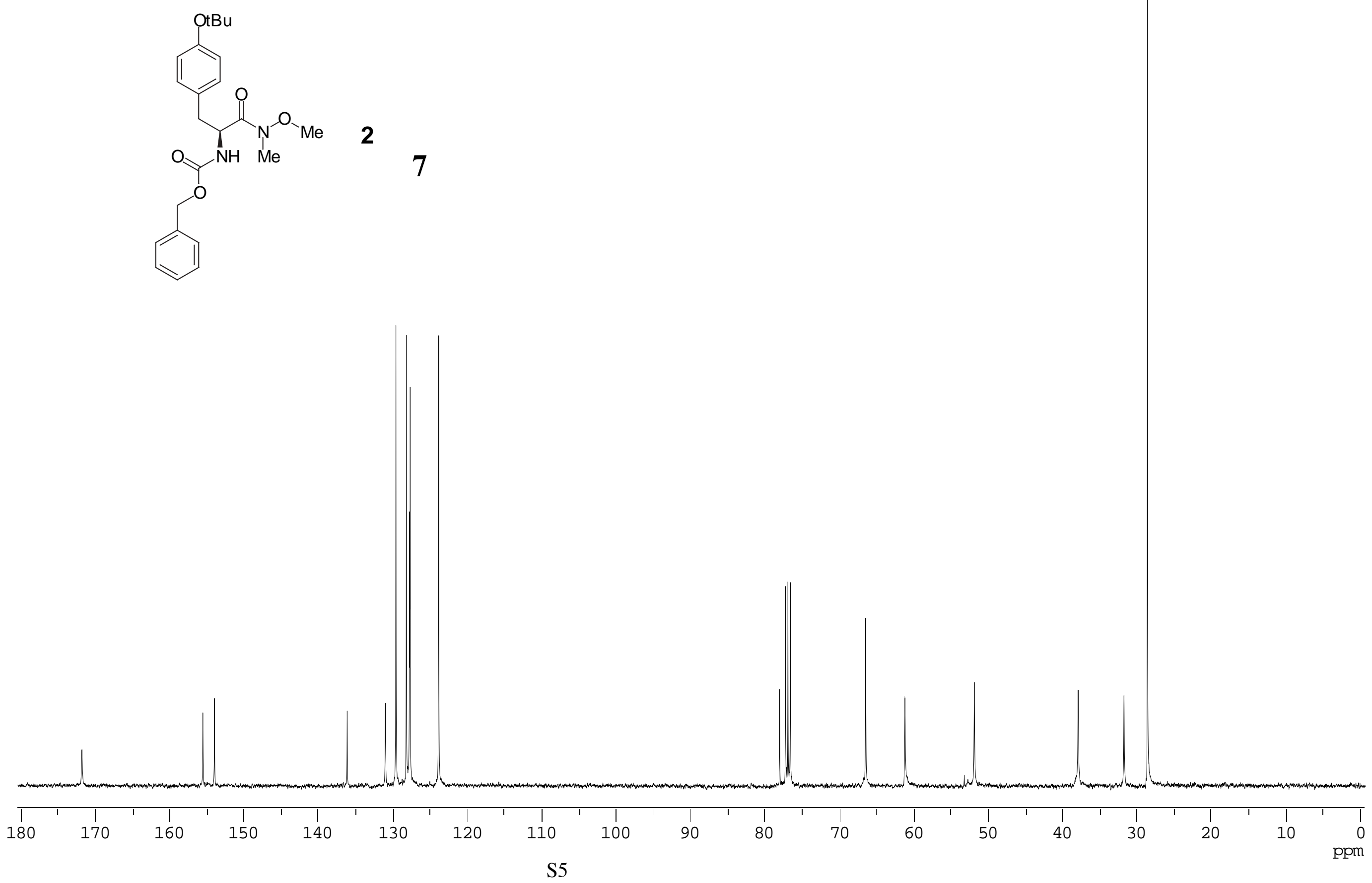


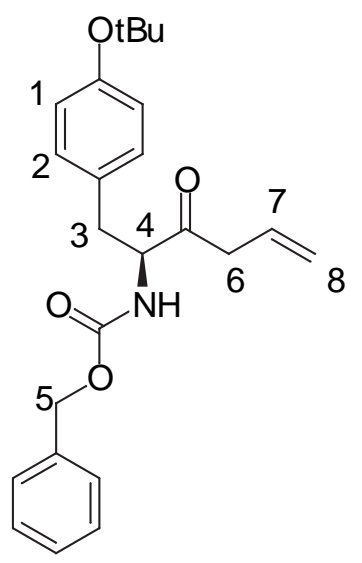

Cbz-arom

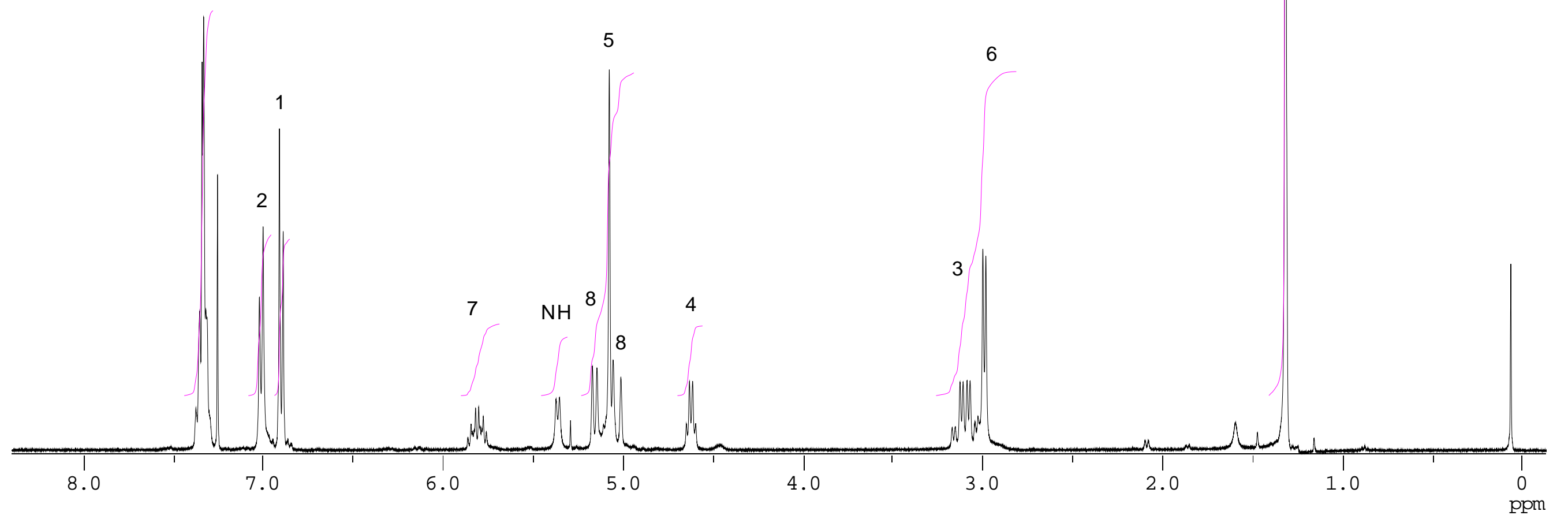




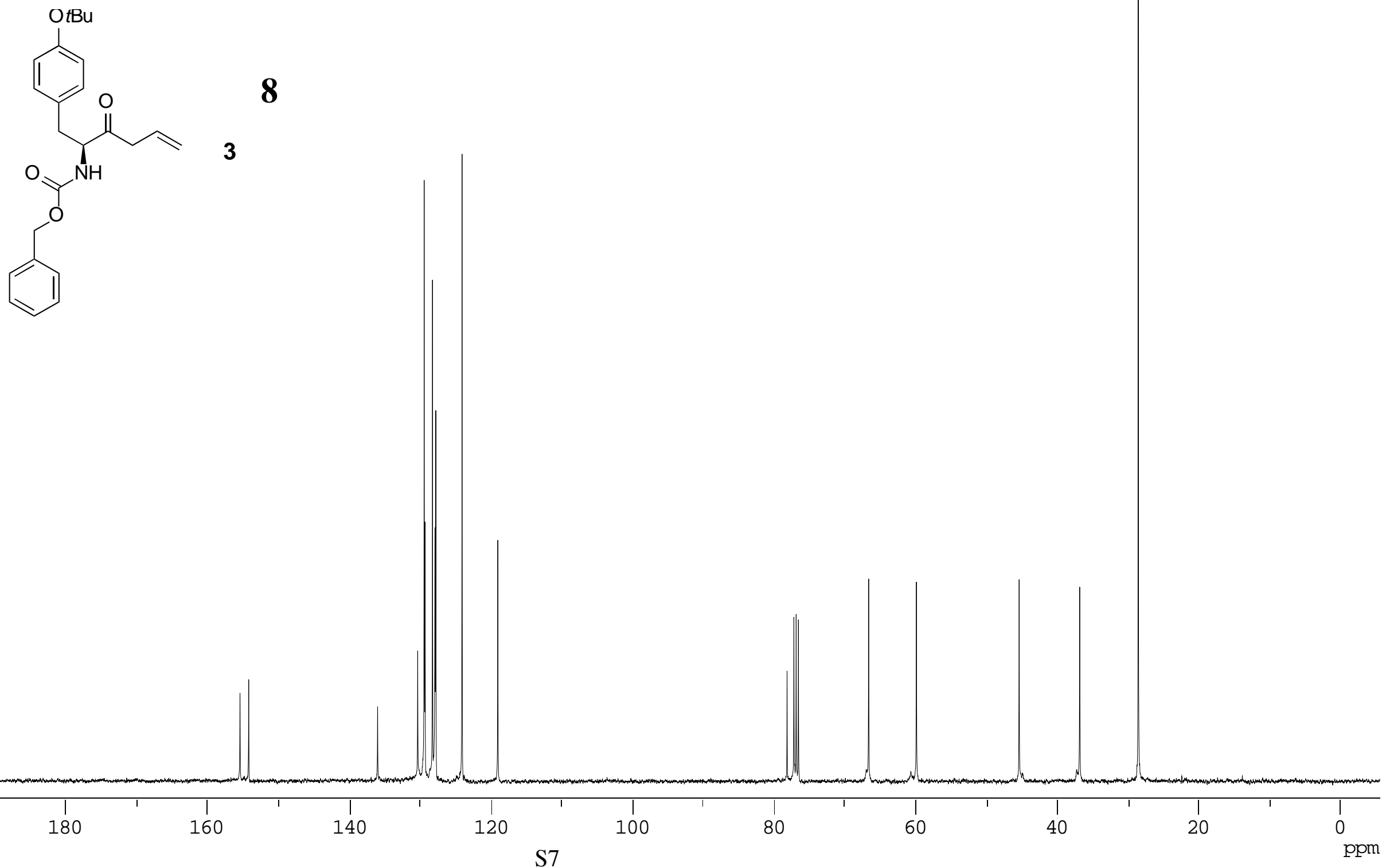




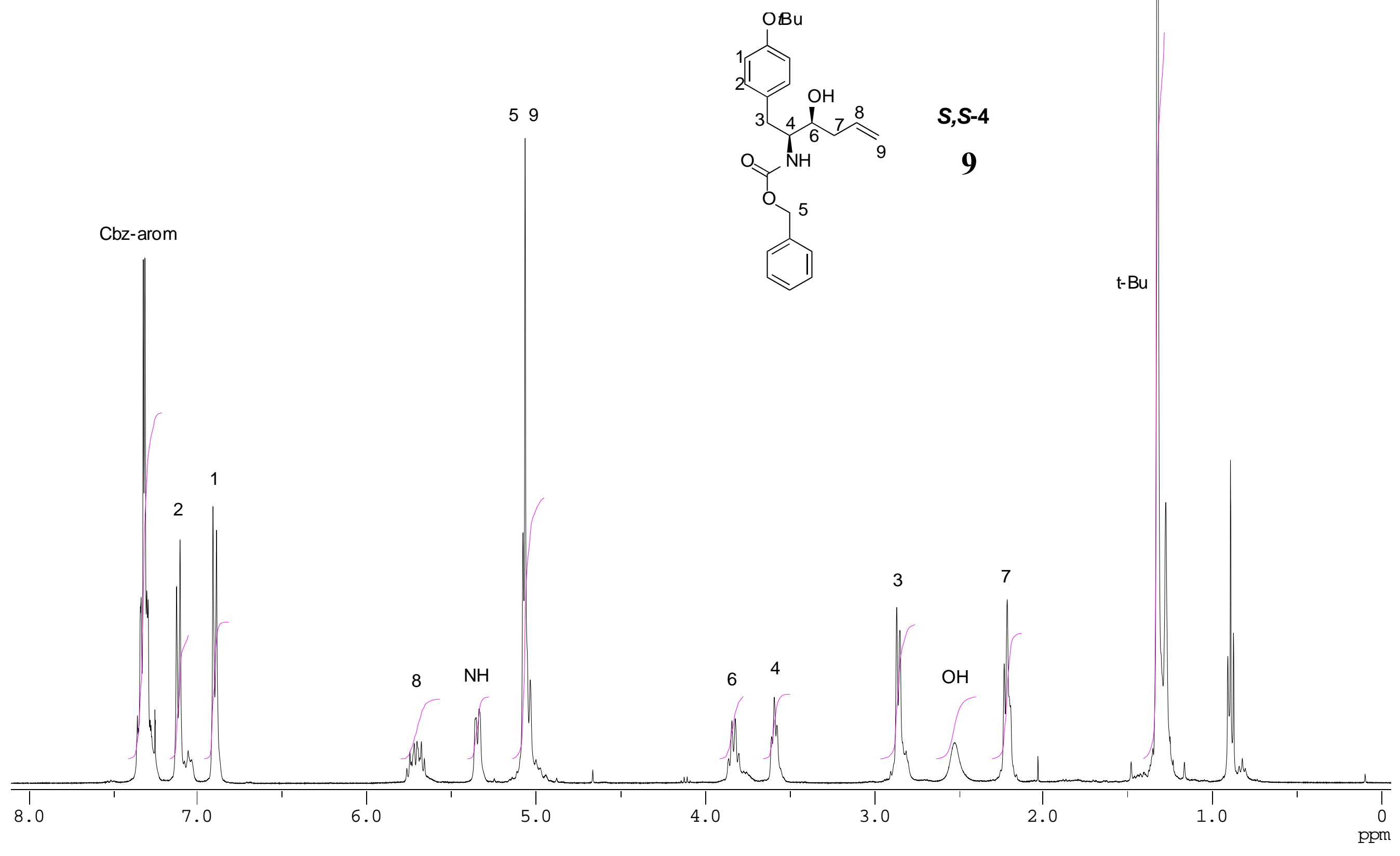




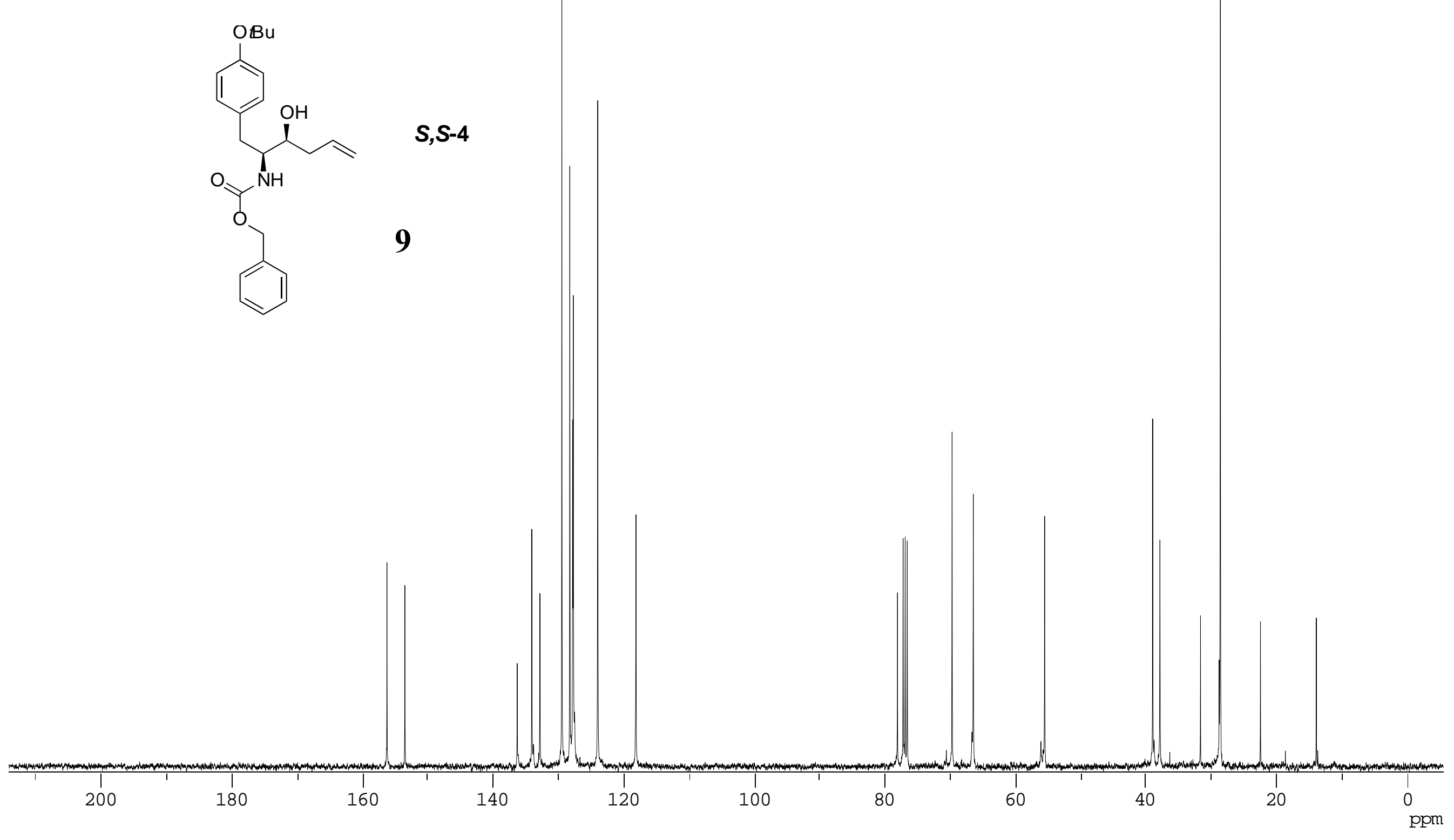




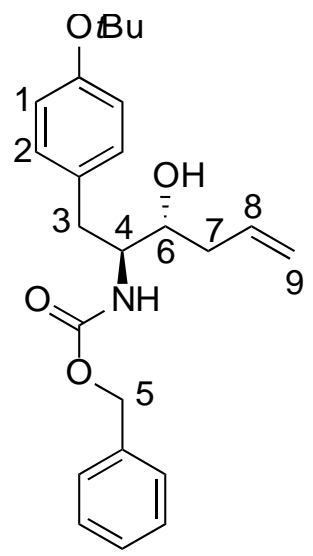

\section{0}

$\mathrm{t}-\mathrm{Bu}$

Cbz-arom

5

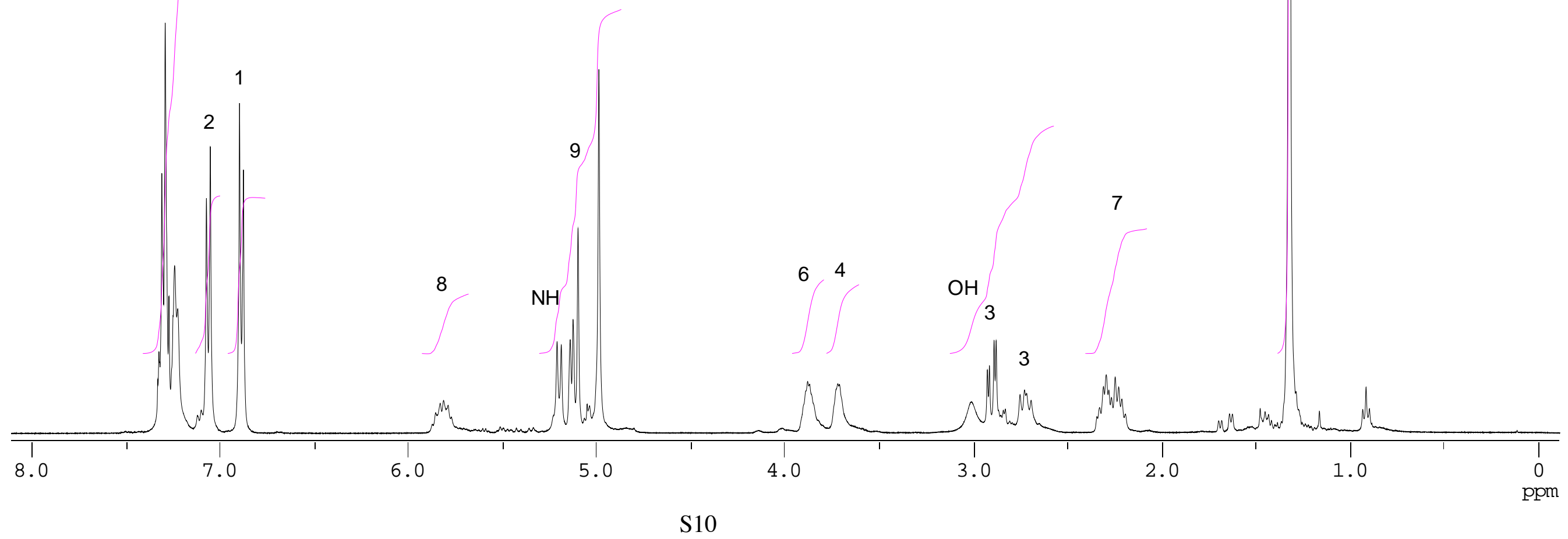




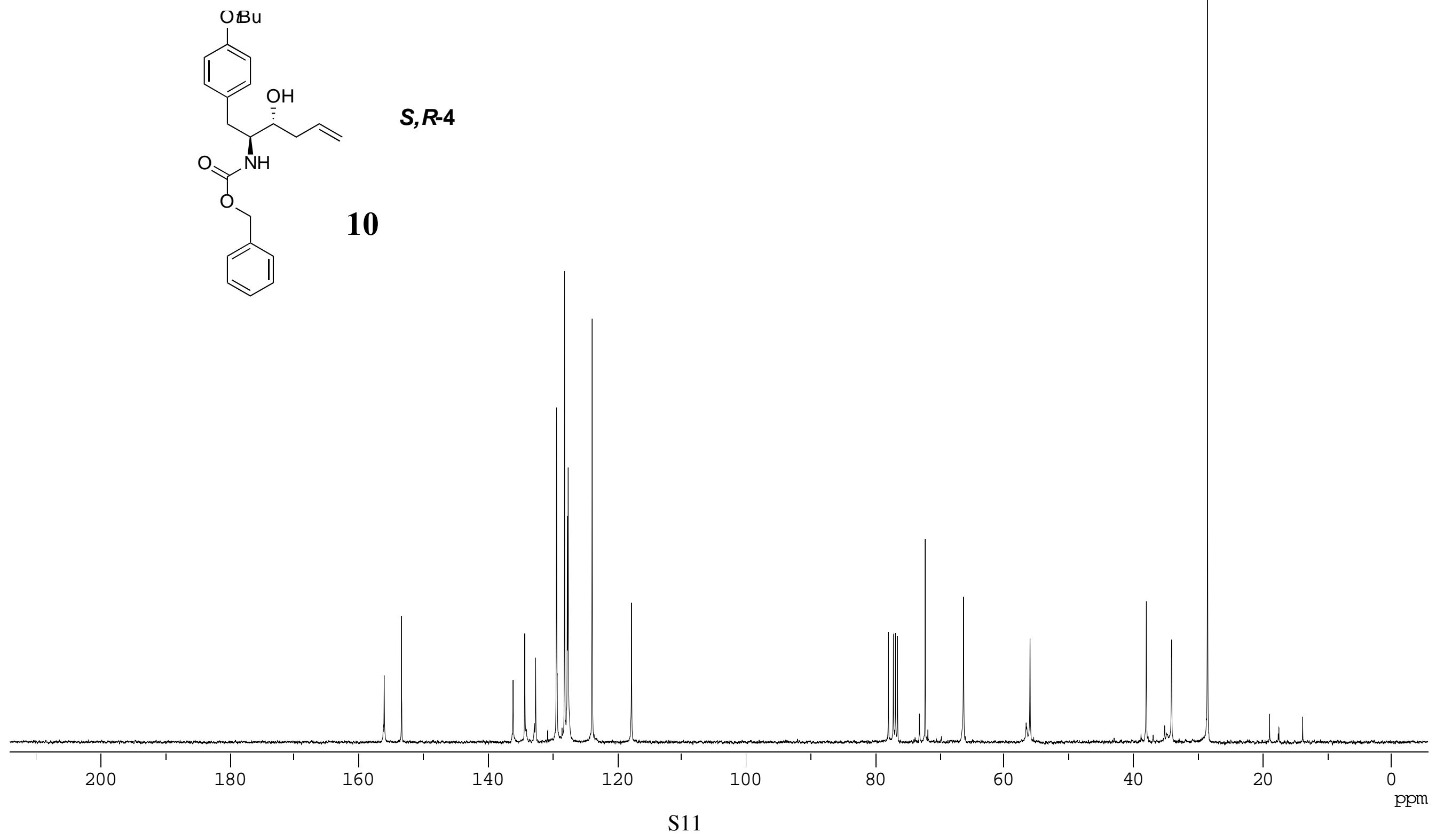



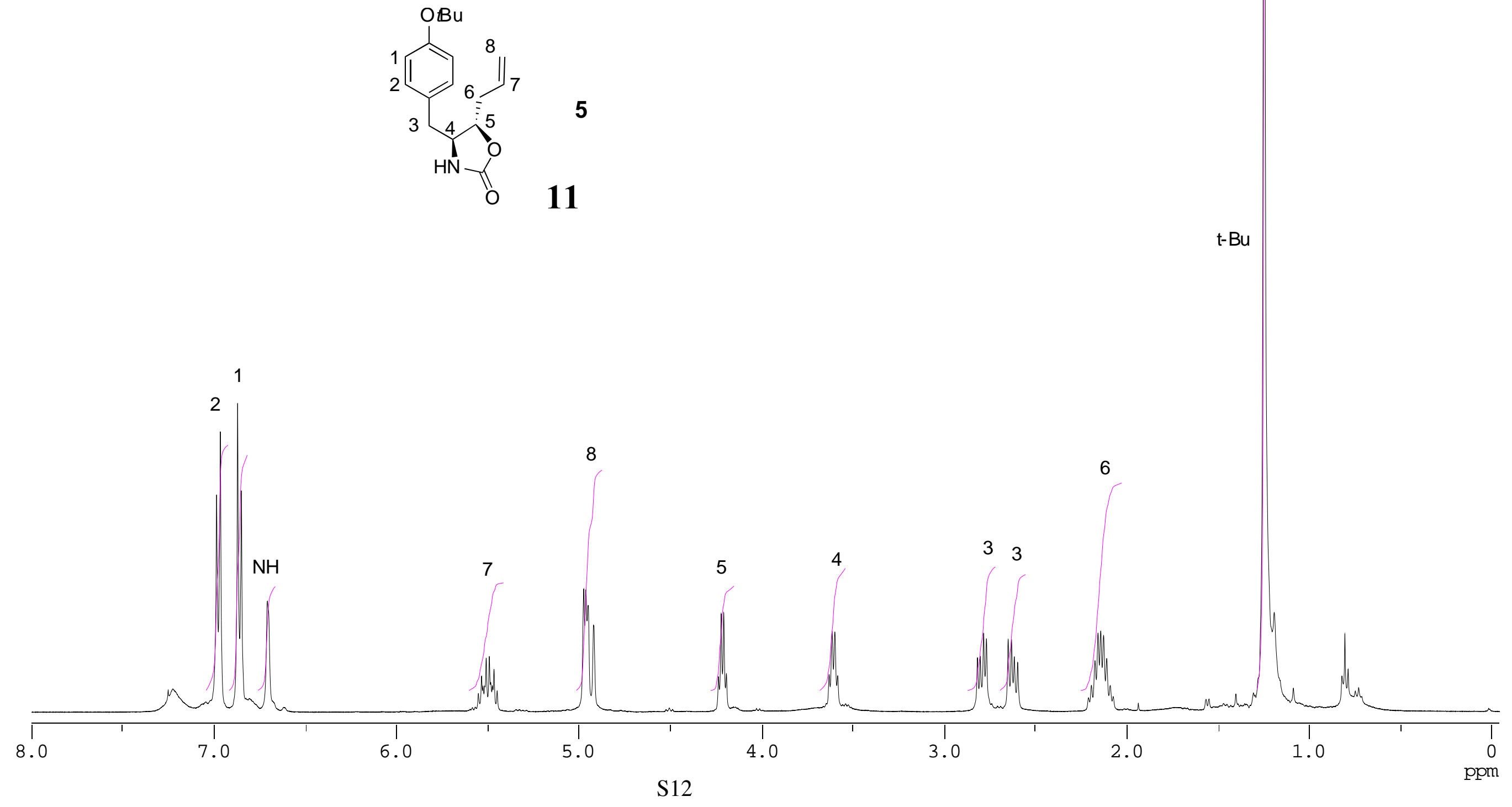


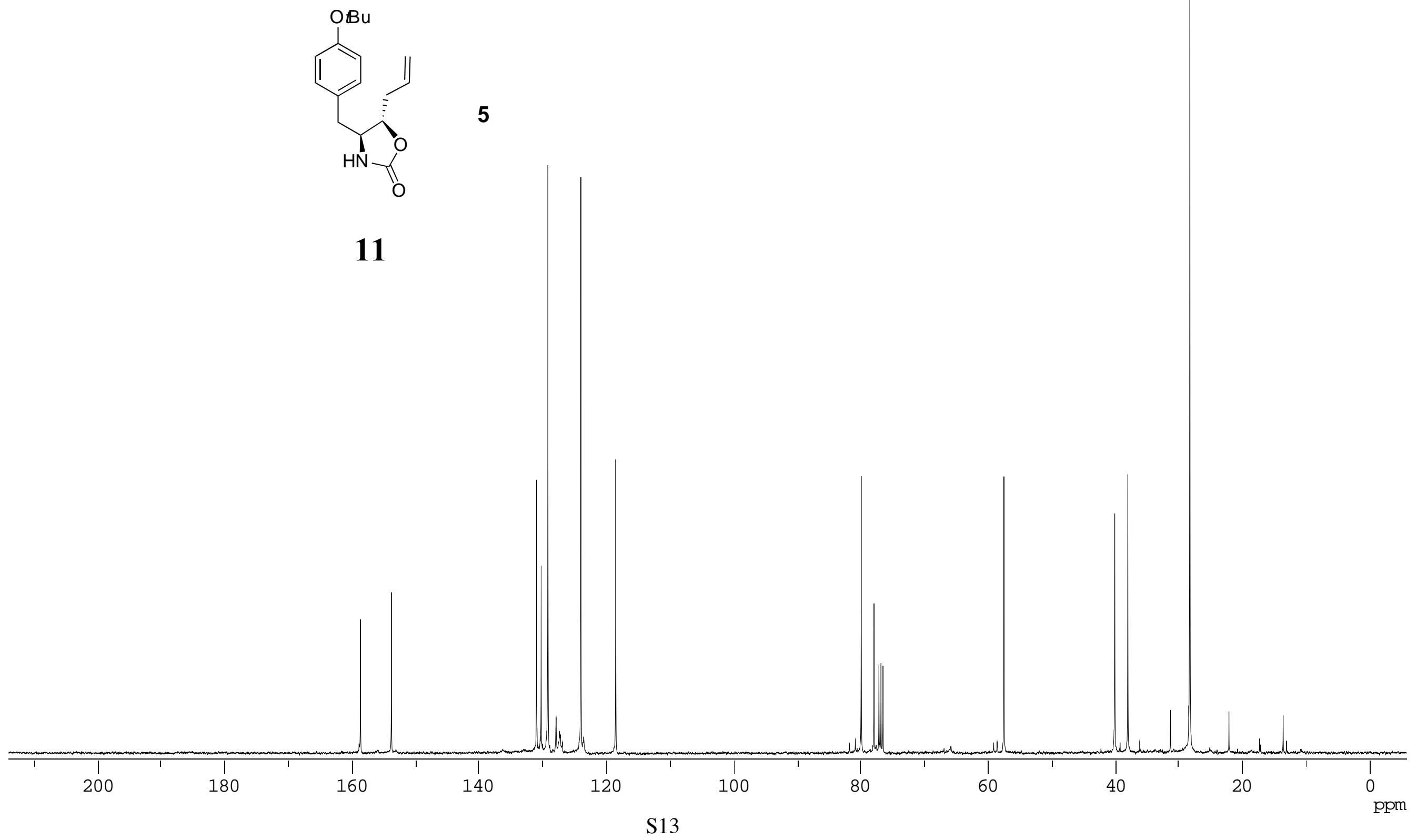




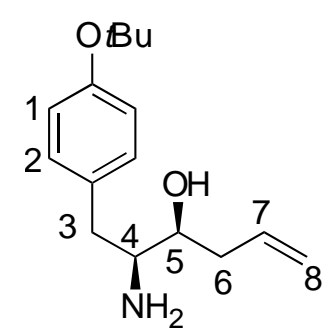

12

$\mathrm{t}-\mathrm{Bu}$

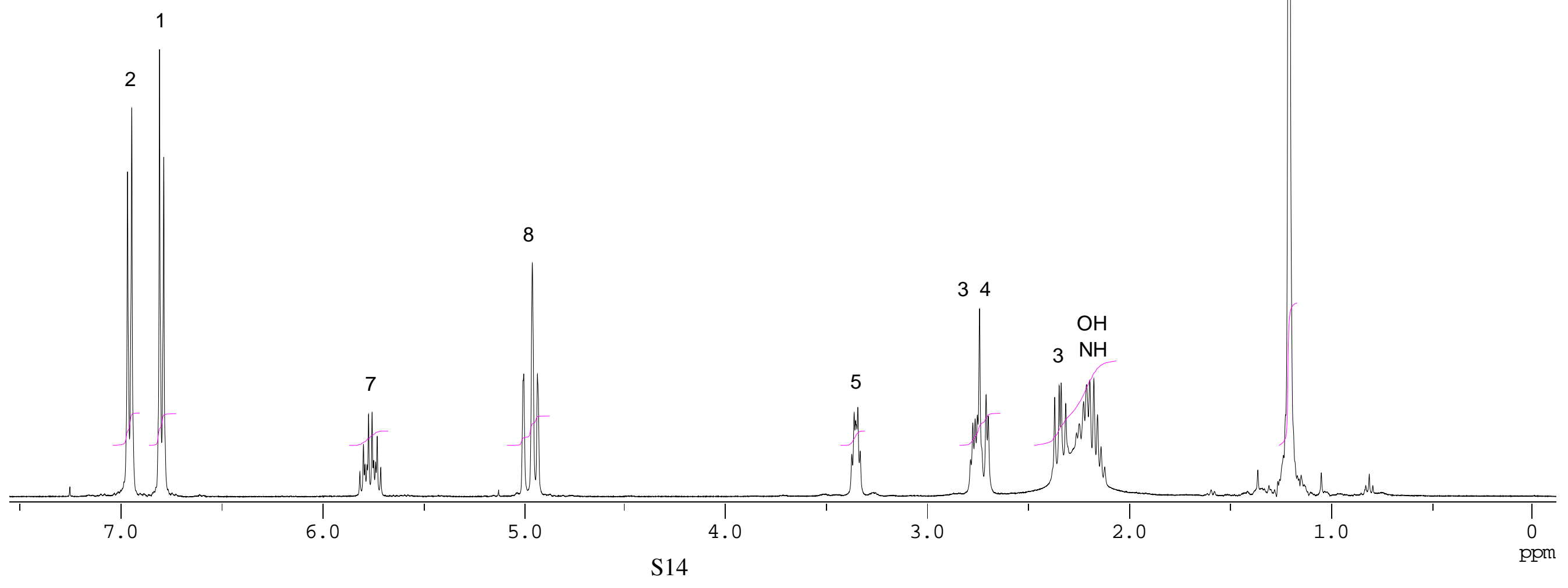




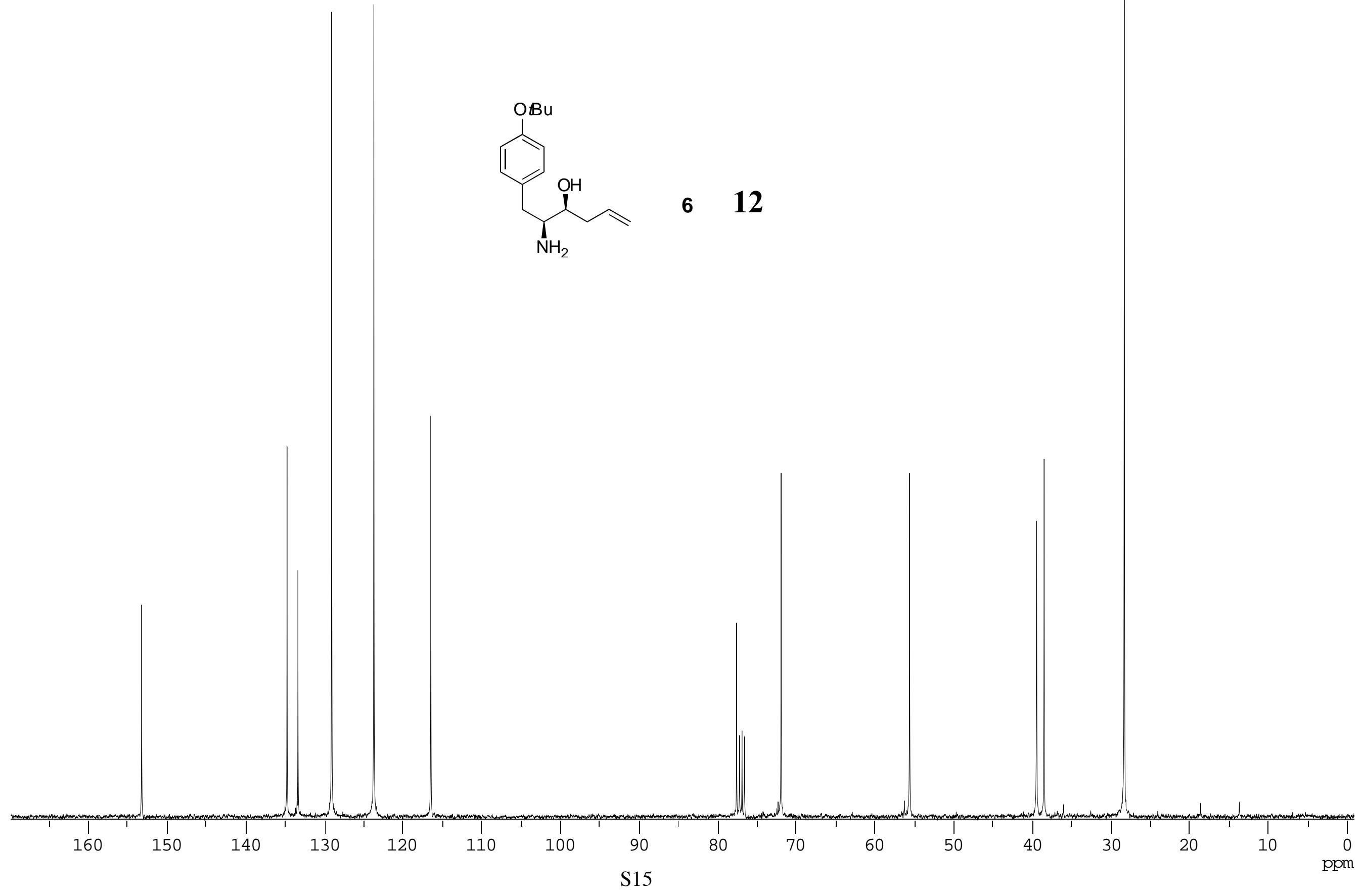




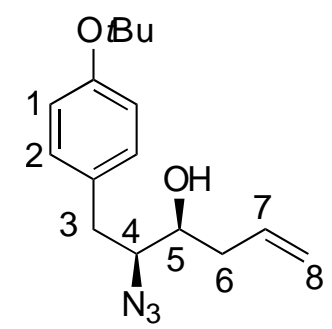

13

$\mathrm{t}-\mathrm{Bu}$

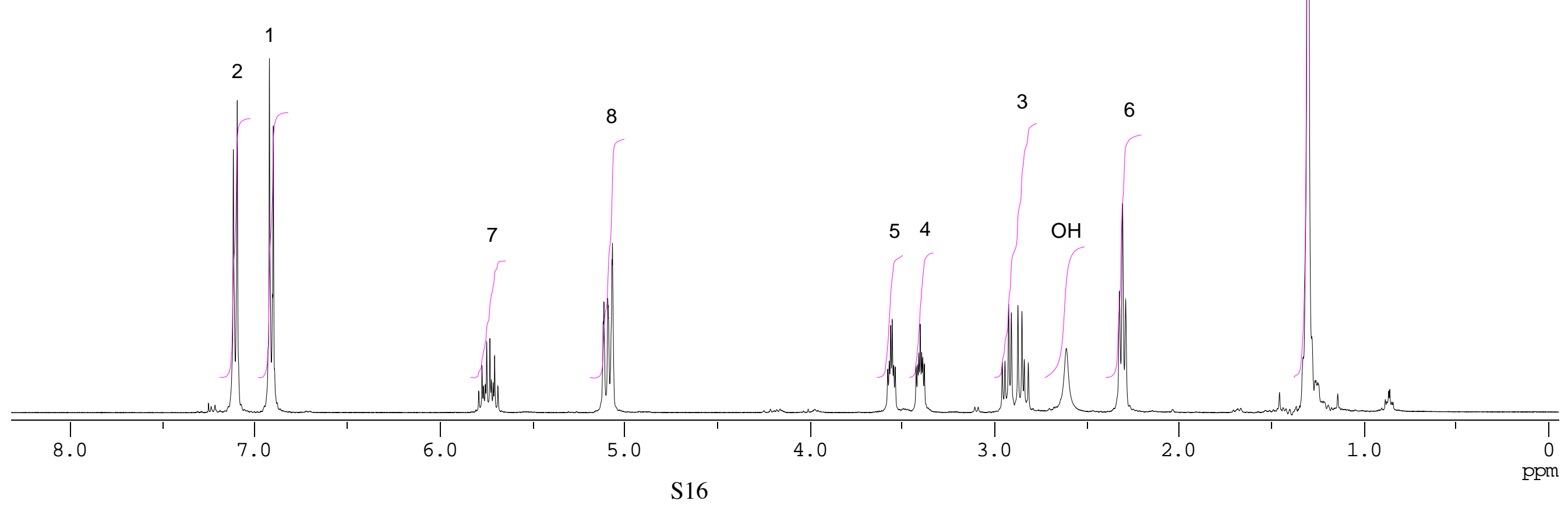




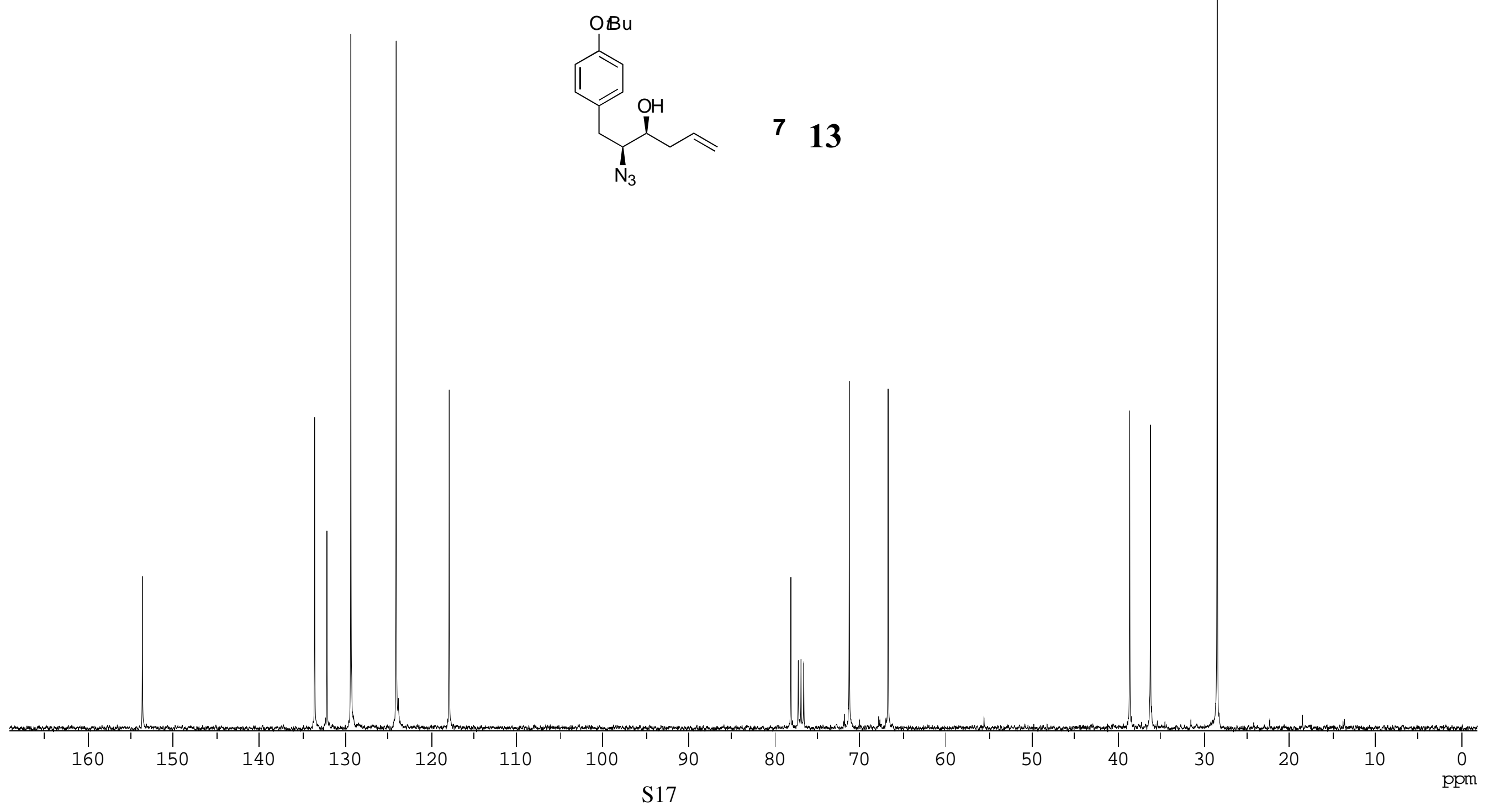




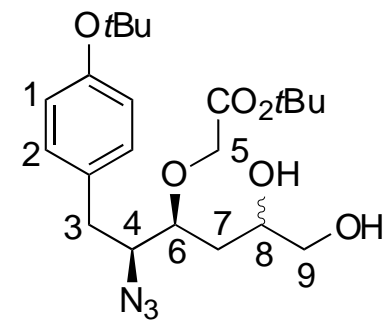

\section{5}

$\mathrm{t}-\mathrm{Bu}$, ester

$\mathrm{t}-\mathrm{Bu}$, ether

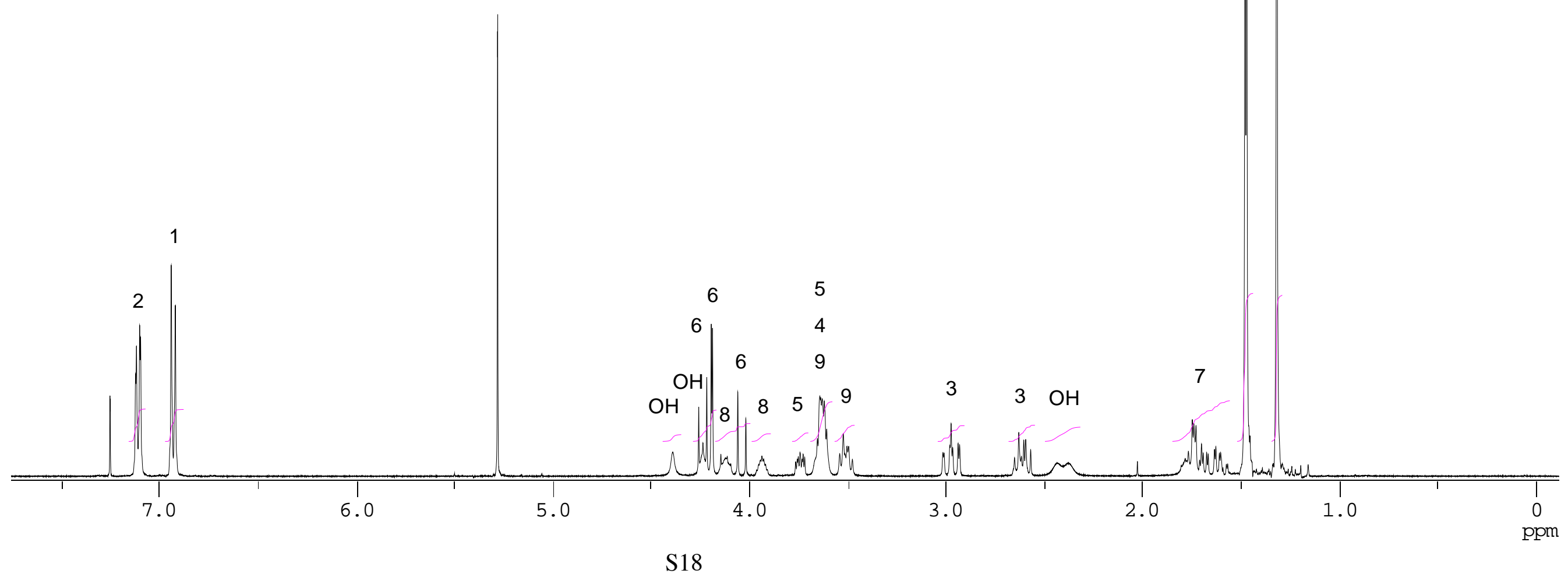




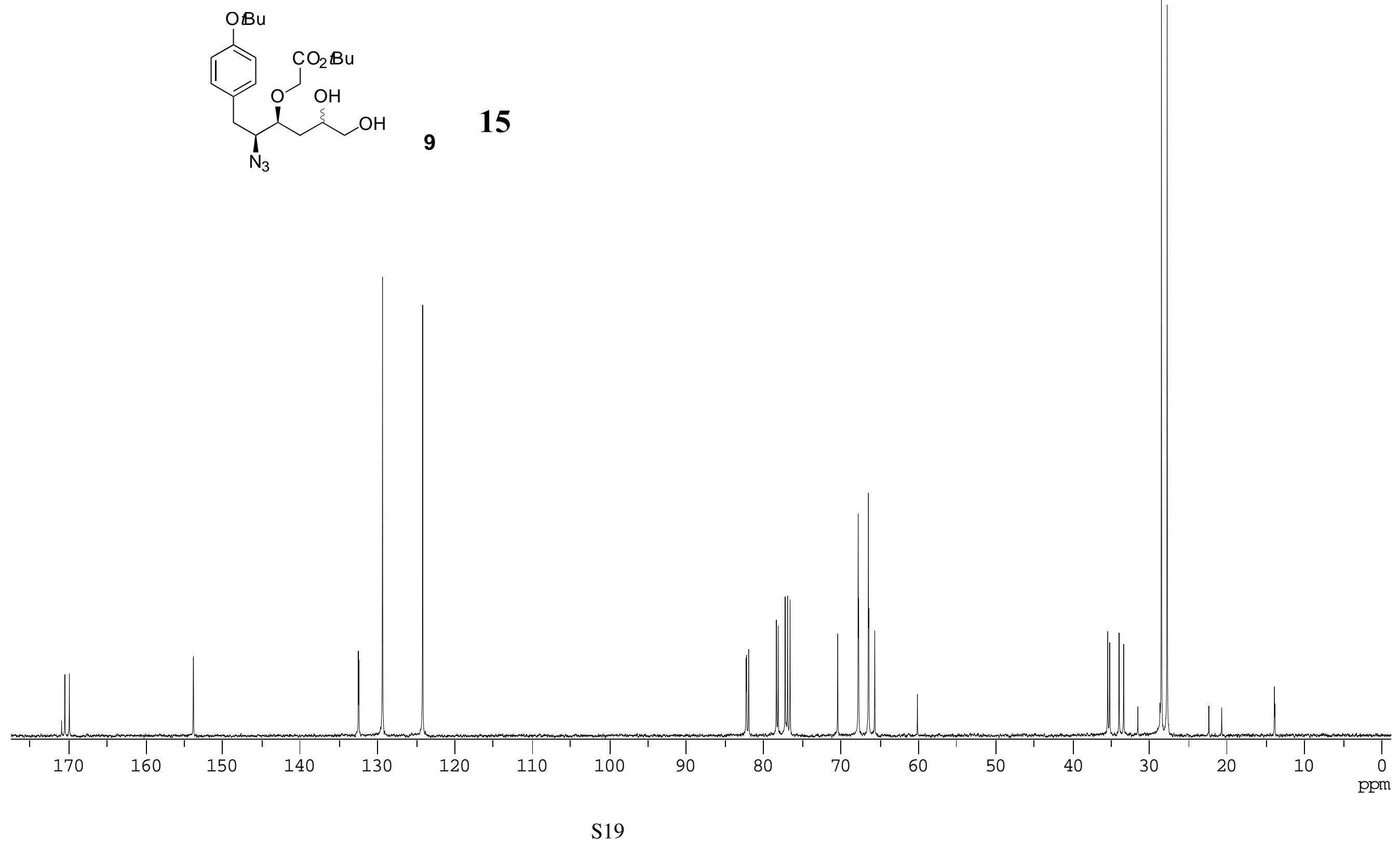




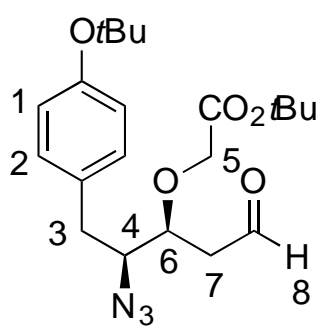

t-Bu, ester

t-Bu, ether

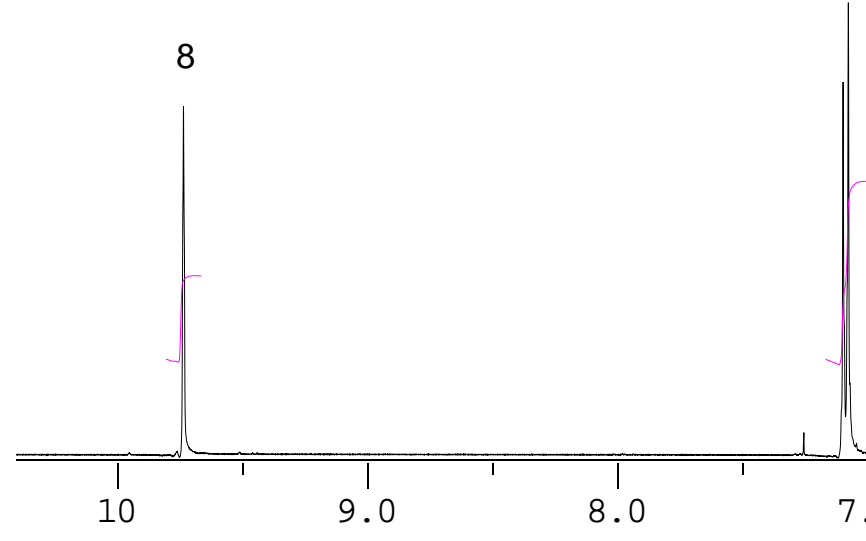

1

2

Heptane
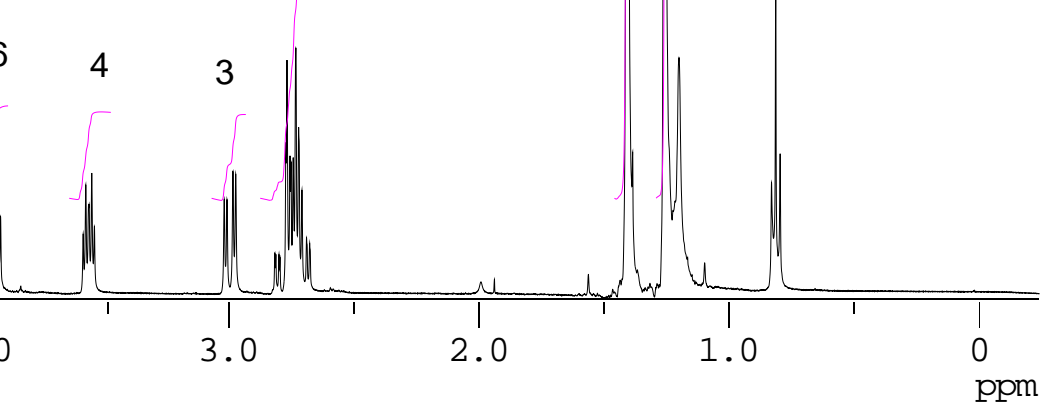


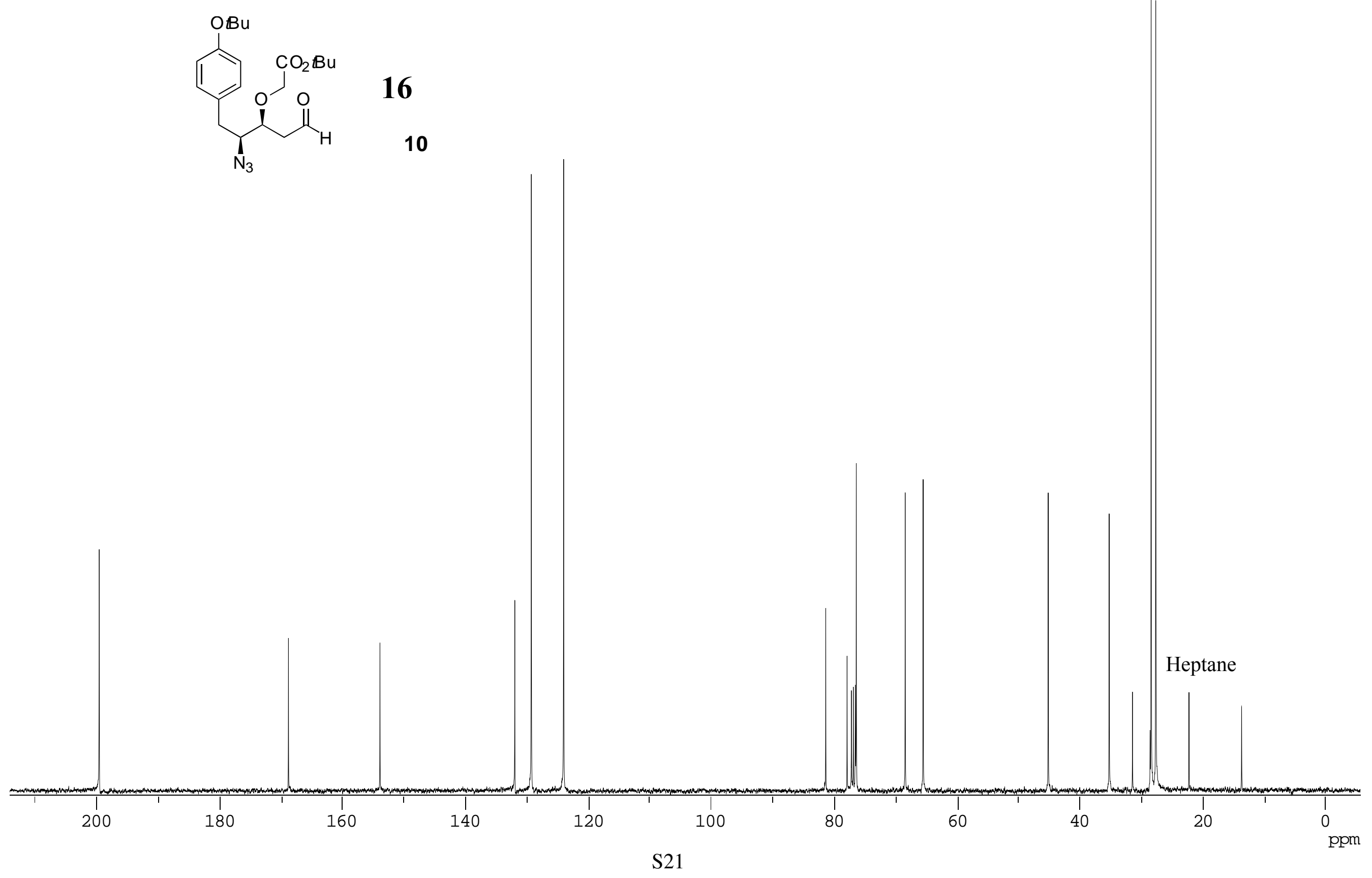




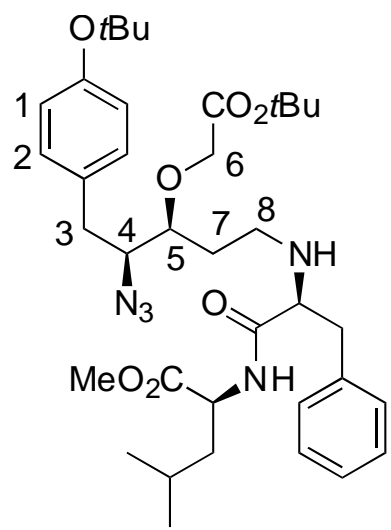

$\mathrm{OMe}$

17

t-Bu, ester

$\mathrm{t}-\mathrm{Bu}$, ether

Phe-arom

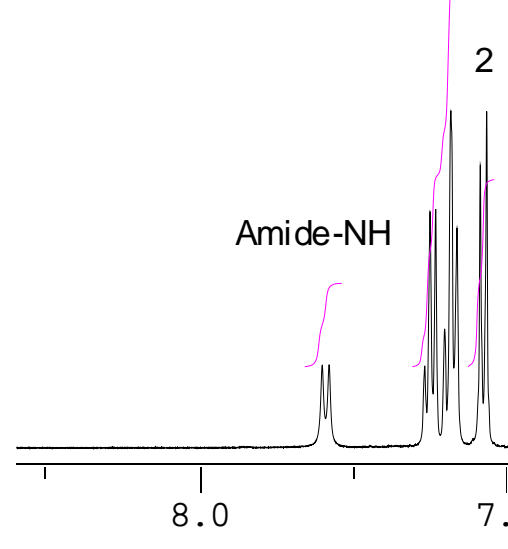

2

1

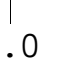

6.0 

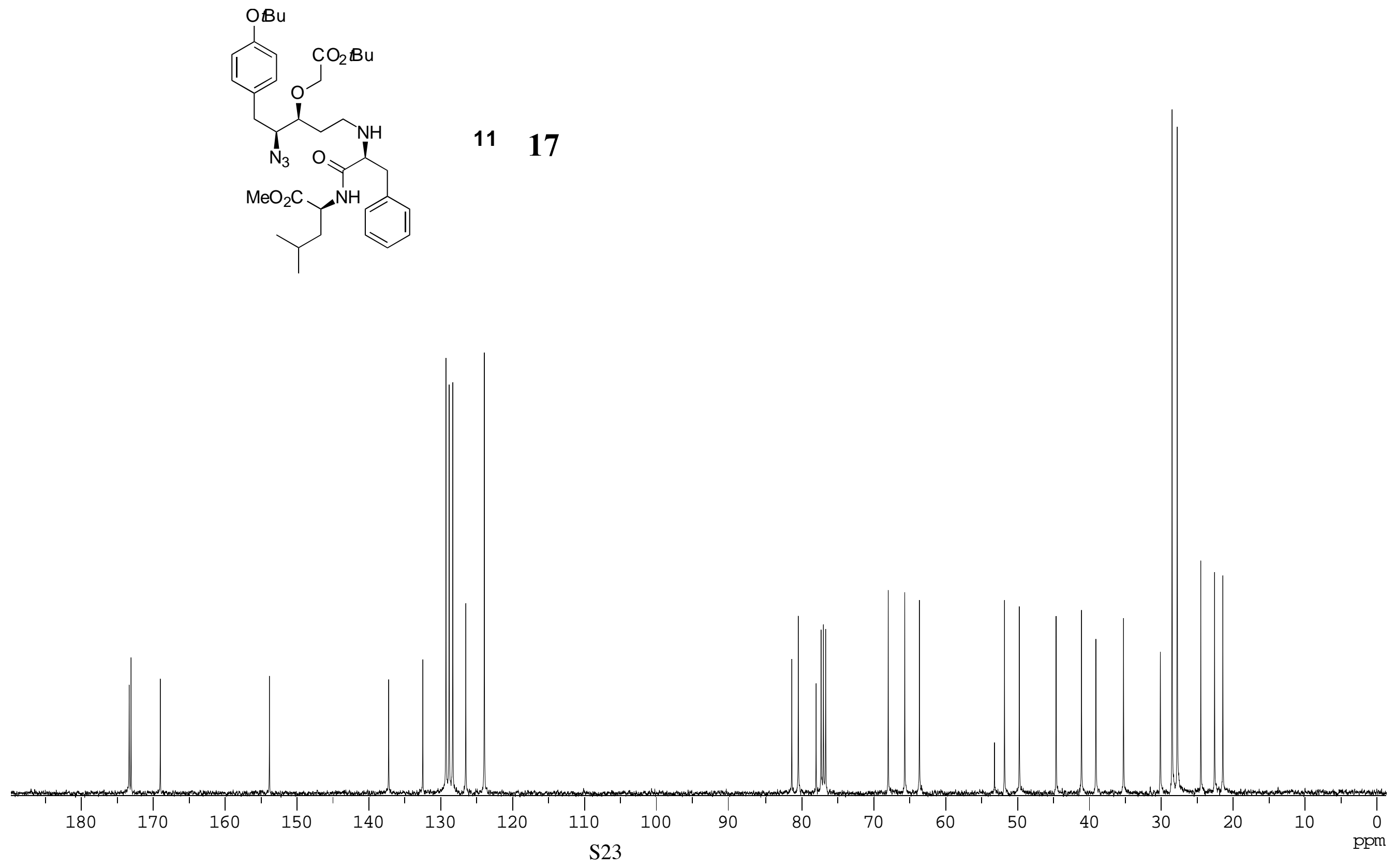


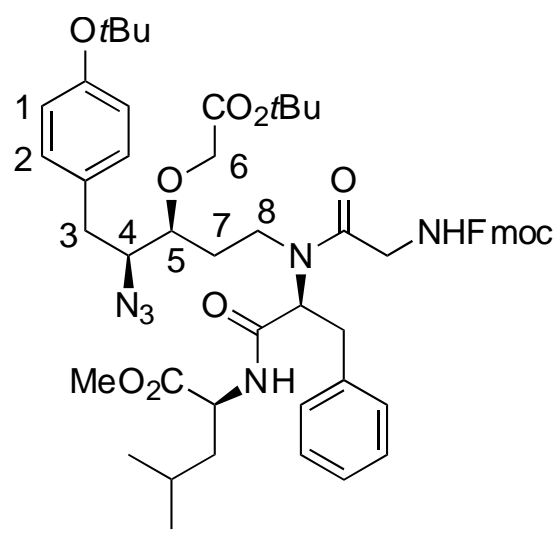

\section{8}

Phe-arom

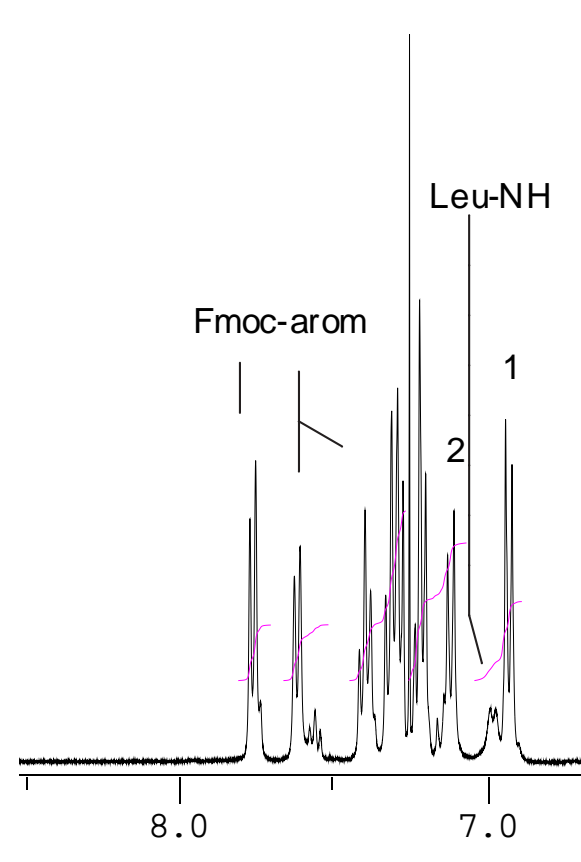

$\mathrm{OMe}$

$\mathrm{t}-\mathrm{Bu}$, ester

$\mathrm{t}-\mathrm{Bu}$, ether

Fmoc- $\mathrm{CH}$

6

$\alpha$-Gly $\beta$-Phe

Gly-NH

$\alpha$-Phe

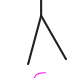

5.0

1.0 


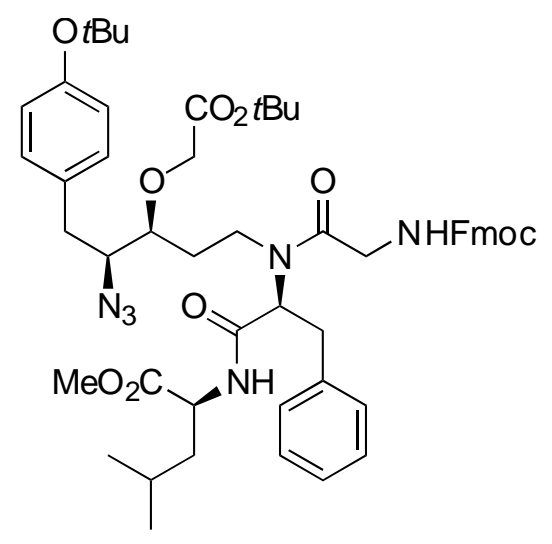

\section{8}




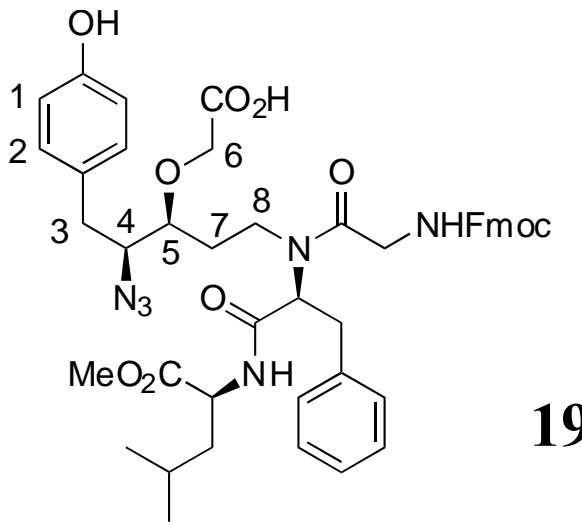

19

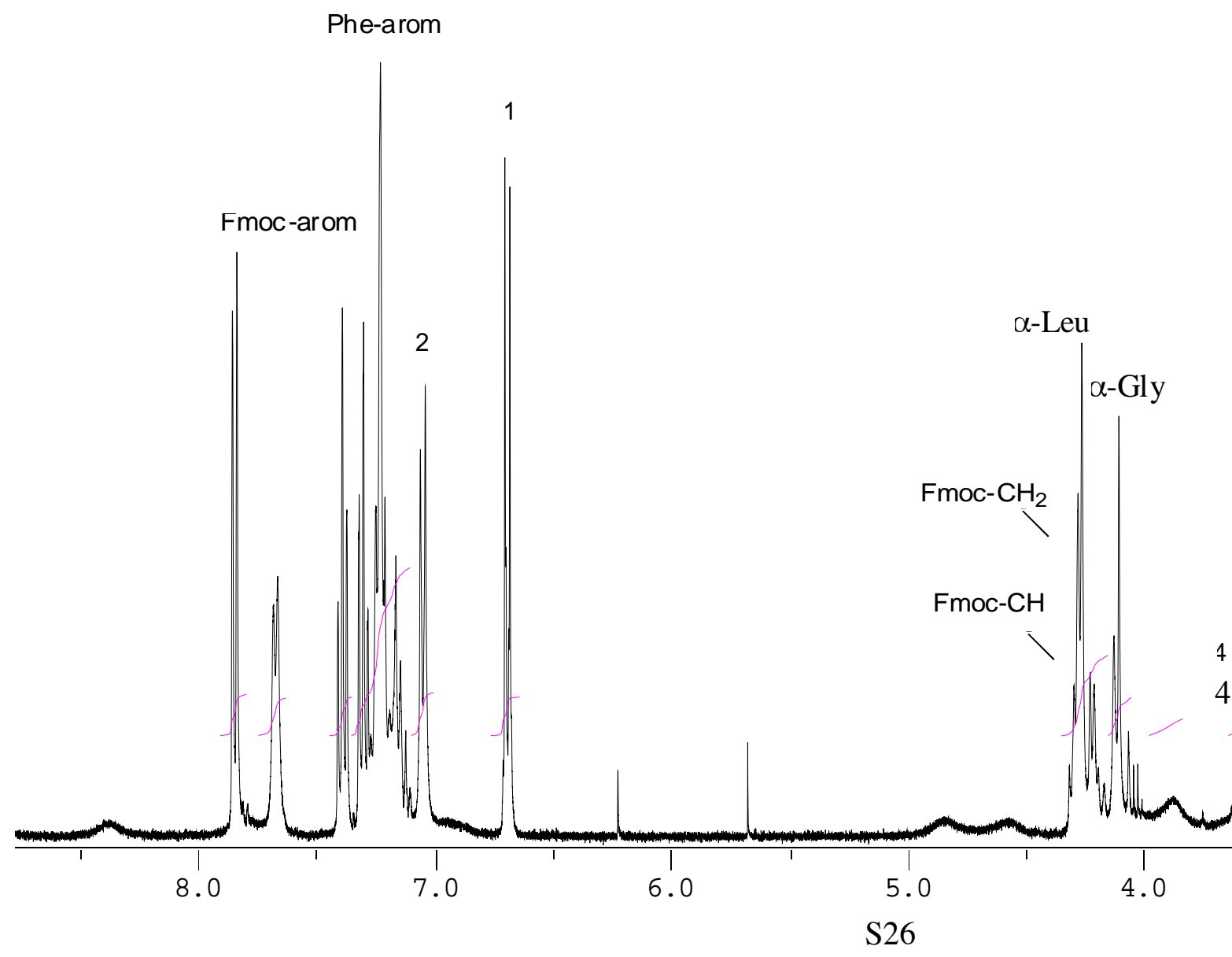

Leu- $\delta$

Leu

\begin{tabular}{ll|l}
5 & $3-$ Leu \\
$\varepsilon$ &
\end{tabular}

7

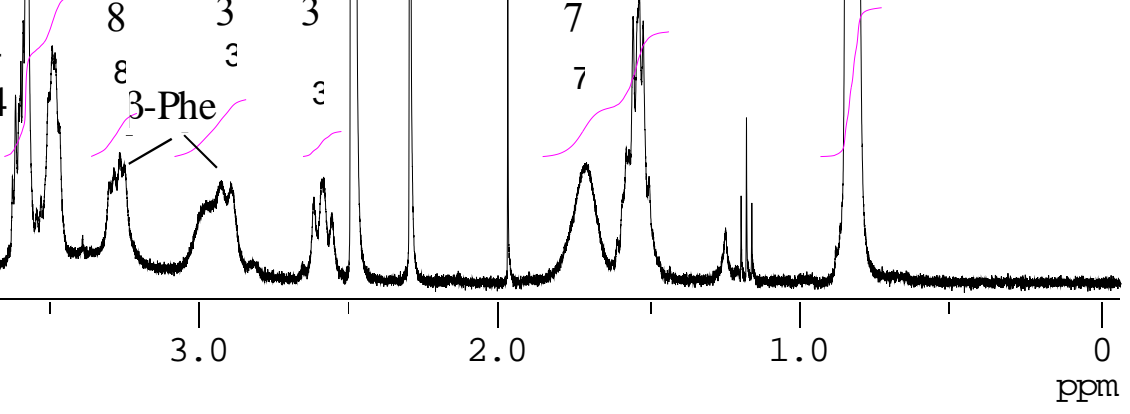




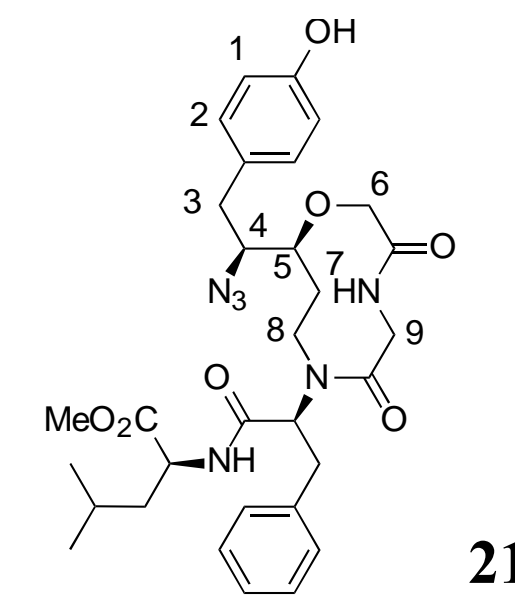

OMe

Phe-arom
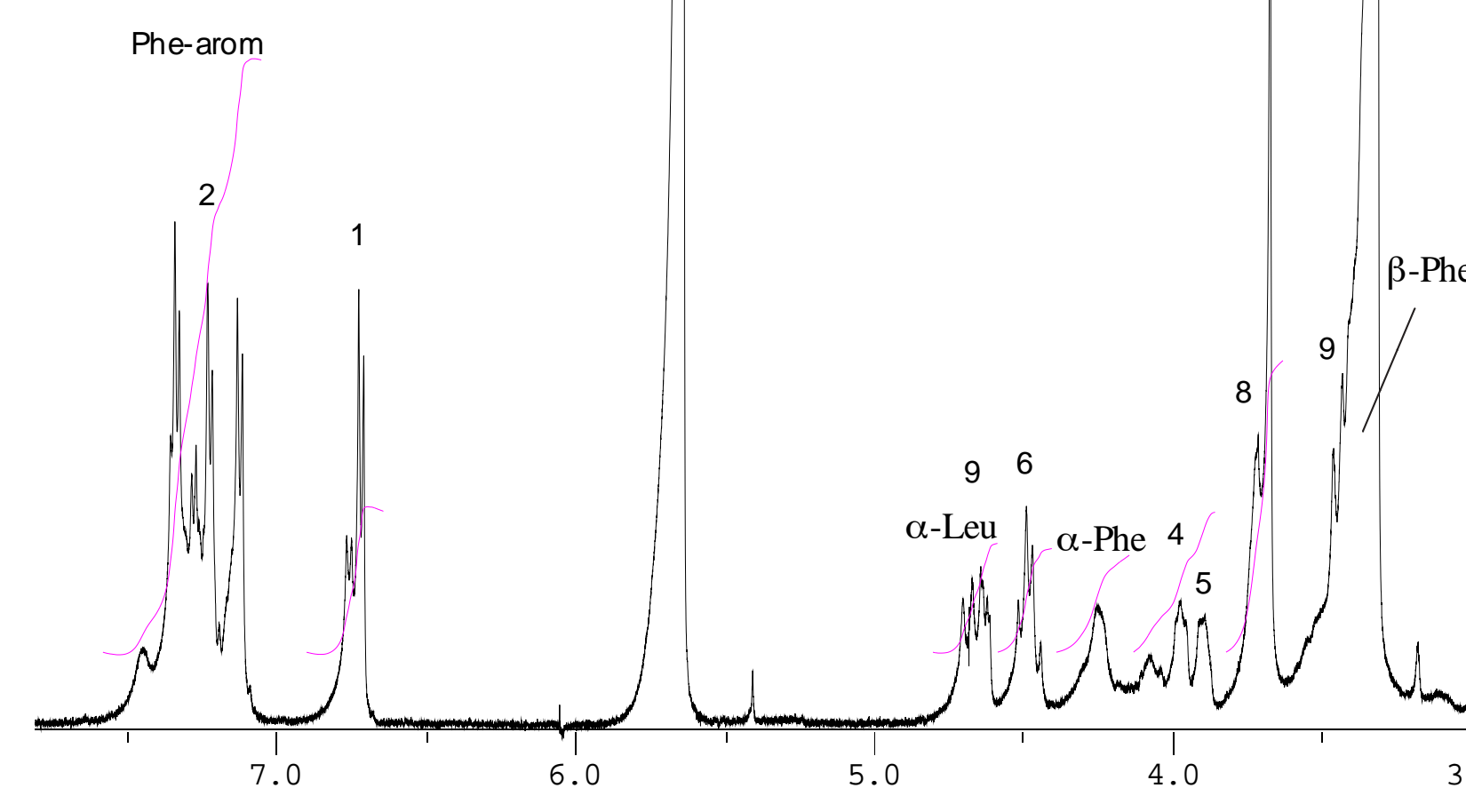

96

$\alpha$-Leu

$\alpha$-Phe 4
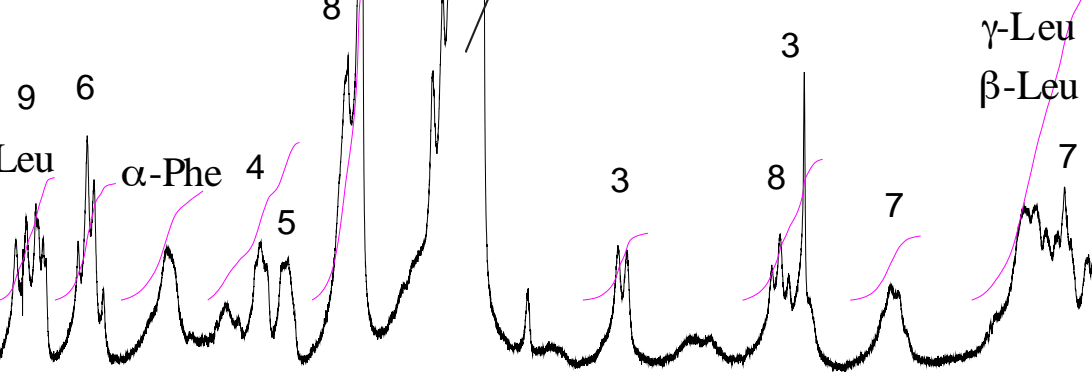

$\beta$-Leu 


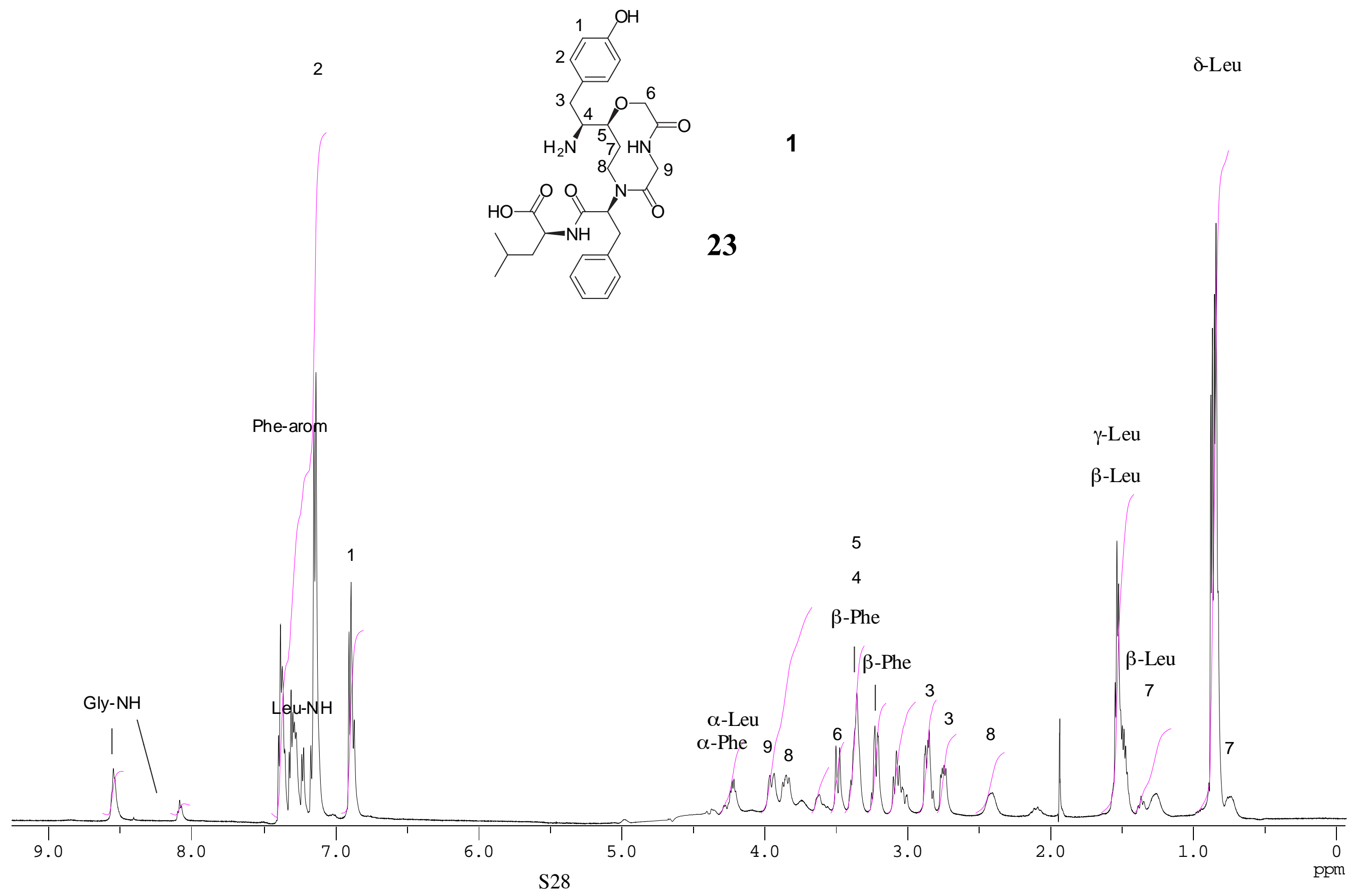

